\title{
ALGUNOS JUEGOS INFANTILES CRIOLLOS E INDIGENAS DEL NORTE ARGENTINO
}

\author{
Por MARIA DELIA MILLAN DE PALAVECINO ${ }^{1}$
}

En algunas zonas del Norte Argentino y sobre el borde del Chaco Salteño, resulta evidente la conjunción de grupos de distintas etnías, hecho motivado por ser la vía de tránsito obligado entre los habitantes montañeses del altiplano andino, los vallistos del área selvática y los grupos indígenas chaqueños, tobas, toba-pilagás, matacos, chunupíes y otros.

En esta vasta área se encuentran vivos elementos, tanto de la cultura campesina europea, como también de la indígena. Coinciden ambas especialmente en aquellos lugares de intensa labor rural o industrial propias de la zona, como es la maderera. En resumen, sobre un estrato primitivo está asentada la cultura europea, existiendo una clara diferenciación entre cada una de ellas. Este hecho es muy visible, principalmente en las escuelas, adonde concurren los niños criollos y los indígenas. Como es sabido, los grupos aborígenes rodean la periferia de los pueblos.

En este estudio de juegos y diversiones, expongo, para su comparación, algunos juegos europeos conocidos y otros autóctonos que son practicados hoy en la zona y en las escuelas del Estado.

La clasificación folklórica del mundo infantil, según Arnold Van Gennep, se funda en las edades del niño y el medio en que vive. Esas categorías establecen una primera etapa en la cual el niño vive junto

${ }^{1}$ Miembro de la Carrera del Investigador del Consejo Nacional de Investigaciones Científicas. Directora del Museo Municipal de "Motivos Populares Argentinos José Hernández". 
al regazo materno y grupo familiar. Más tarde ingresa a la escuela y aprende a moverse dentro de una disciplina, estableciendo su "código de honor", e imitando sistemas propios de los adultos.. Comienza la acumulación de "tesoros" y la formación de equipos donde no se admiten "extranjeros". Otra etapa corresponde al período de vacaciones cuando el niño, libre ya, se individualiza. Esta sintesis expresa a grandes rasgos el pensamiento de Van Gennep. La clasificación del sabio. folklorista francés se adapta al estilo que desarrollan los nin̉os indígenas y que describo en segundo término.

En el hoy Instituto de Antropología, se custodian los tomos de la "Encuesta de Folklore"; durante la dirección del Prof. Juan Alfonso Carrizo me fue facilitado el acceso a esta documentación inédita.

Hace más de cuarenta años que en el territorio de nuestro país se efectuó la mencionada "Encuesta", a cargo del Instituto Ricardo Rojas de la Facultad de Filosofía y Letras de la Universidad de Buenos Aires, con la colaboración del Consejo Nacional de Educación. La encuesta, proyectada sobre el conocido Cuestionario de Sebillot fue contestada por los maestros de todo el país, quienes recogieron valiosísimas contribuciones del saber popular, obtenido de adultos, a lo que se sumó, además, las respuestas de los escolares.

Este aporte o censo, en su conjunto, puso de manifiesto la vigencia de los fenómenos folklóricos, resultando una abrumadora realidad en la descripción de costumbres, creencias, leyendas, supersticiones, esparcimientos, etc.

De él extracté las noticias y tabulé los datos sobre juegos infantiles, lo que dio como resultado, visto con criterio etnográfico y casi sin excepción, una totalidad de juegos de origen netamente europeo. Esto es lógico y así debía esperarse, pues la encuesta tuvo su mayor registro en las zonas de población de ascendencia hispana. En su fase final, dicho estudio quedó depositado en 1957 en el Museo del Noroeste de la provincia de Tucumán.

Posteriormente, durante los viajes de investigación etnográfica realizados al área chaquense tuve oportunidad de documentar, en el campo de trabajo mismo, los juegos y entretenimientos entre distintos grupos aborígenes. Quedó así establecido el carácter indígena manifestado en el desarrollo de cada juego. Los grupos actuaban por separado, adultos o niños; el carácter de la expansión en que se movían "per se", o en su fantasía, ponía en vivo su relación con el ambiente y con los elementos u objetos que lo poblaban, fueran estos vivos o inanimados. 
Los ejemplos aquí presentados no son todos los juegos infantiles; su estudio demandaría la recopilación y la clasificación de los pertenecientes a ambas edades; figuran tan sólo unos pocos ejemplos.

El universalmente conocido "juego de hilos" señala bien, aparte de su difusión sudamericana, el estilo de un mundo poblado de realismos y de fantasías (ver figs. 1 a 15).
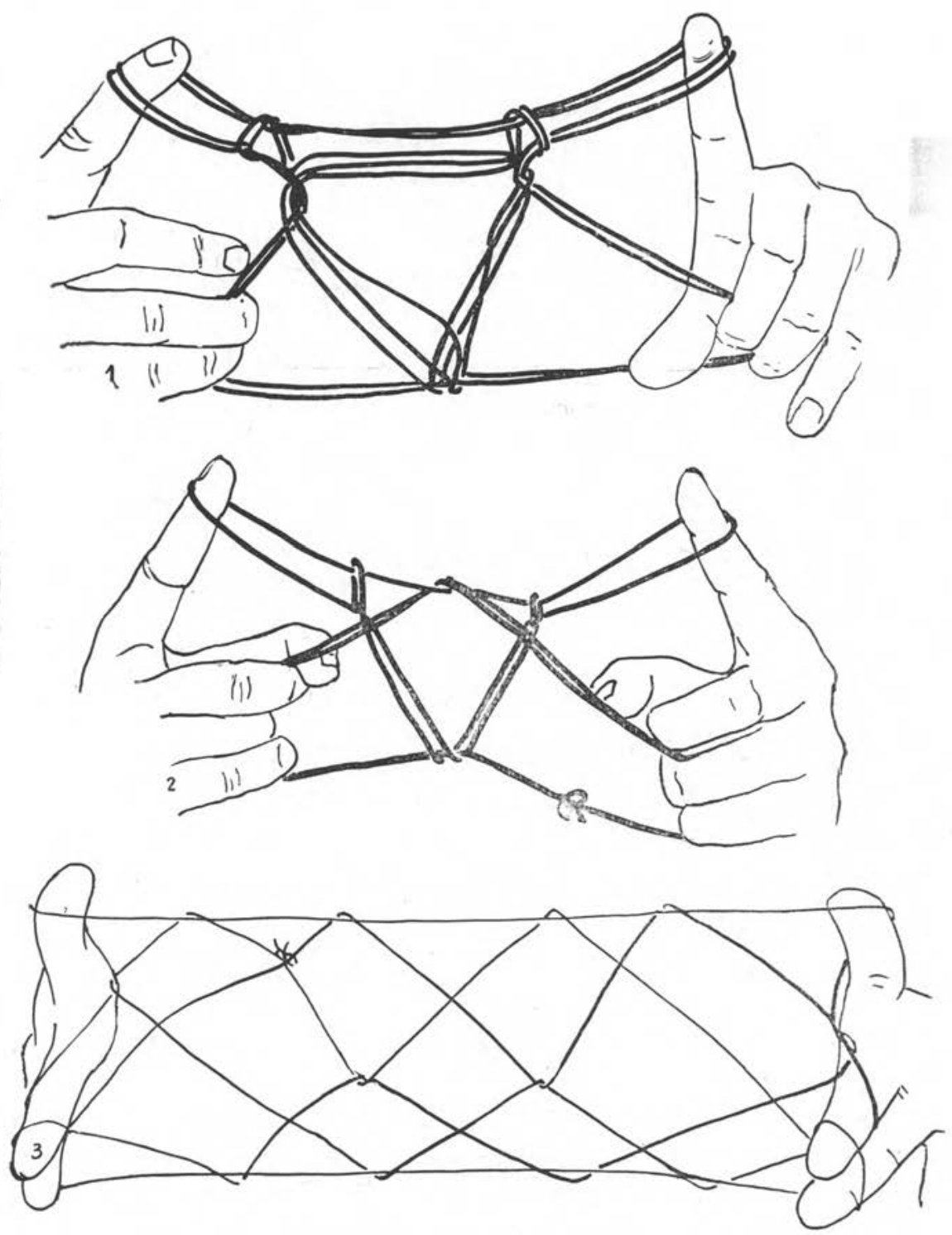

Fig. 1-3. - Juegos con hilo; indígeuas (explieación en pág. 9) 
En otros casos, las figuras de alfarería (animalitos, figuras humanas) y las realizadas en la tierra, como laberintos, muñecos de formas abstractas hechos con huesos, caracoles y otros materiales, pueden tener un valor de conjuro propiciatorio o de comunicación.

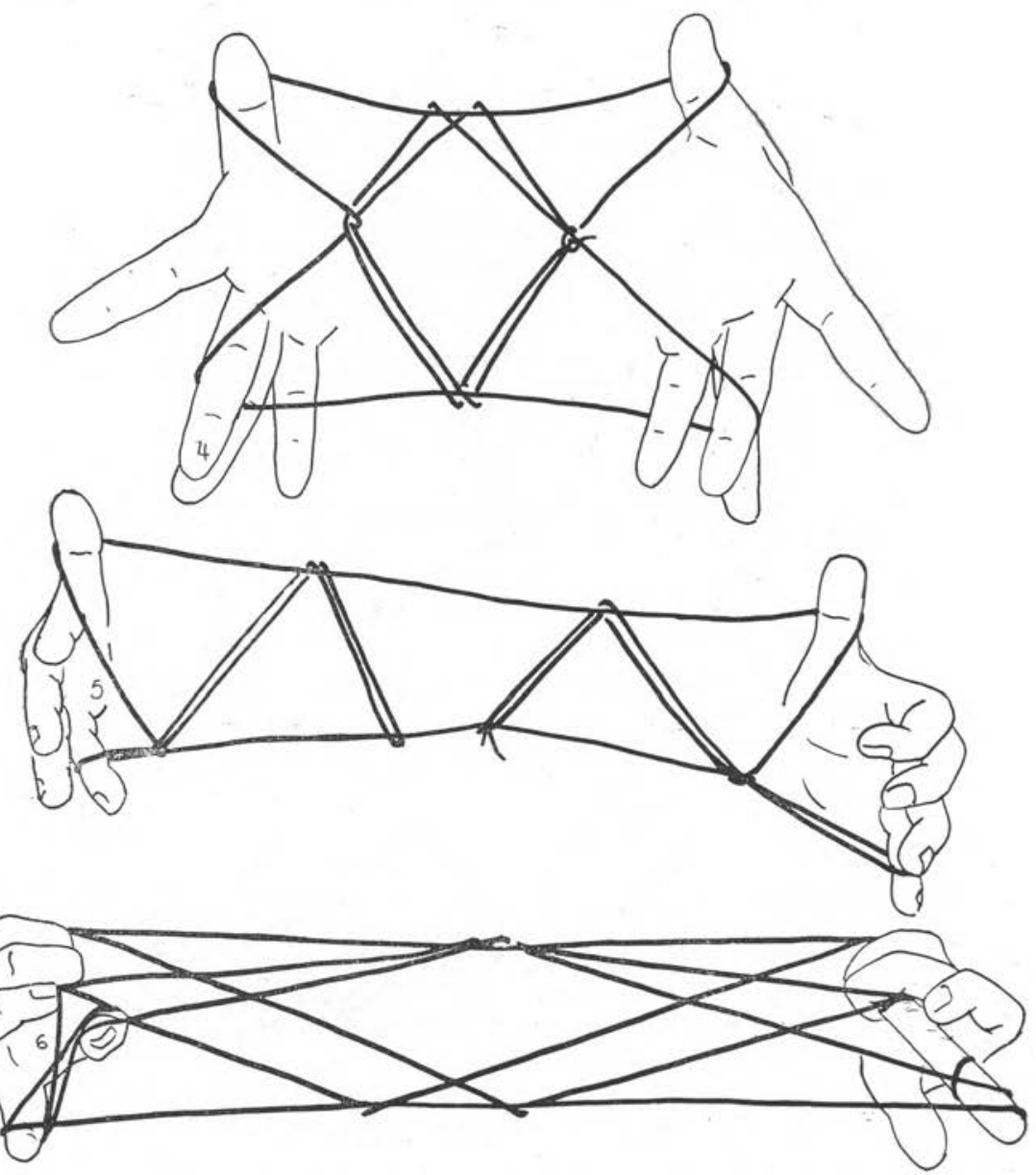

Fig. 4-6. - Juegos eon hilos indígenas (explicación en pág. 9)

El mundo indígena de los juegos está aún por ser estudiado profundamente.

Las provincias del norte argentino reunieron un nutrido acervo de la vida anímica con leyendas referentes a las creencias populares y fábulas, donde se mezclan su origen europeo y los rasgos que denotan la fauna, la flora y algunos aspectos americanos. Son comunes y se 
destacan por su frecuencia las leyendas del cacuy, la calandria y el crespín, las fábulas de Don Juan y Don Quirquincho, el toro de las astas de oro y supersticiones relativas a fenómenos naturales: tormentas, rayos truenos, eclipses, fuegos fatuos. Están presentes también formas comunes de brujería: entre fantasmas y aparecidos figuran el

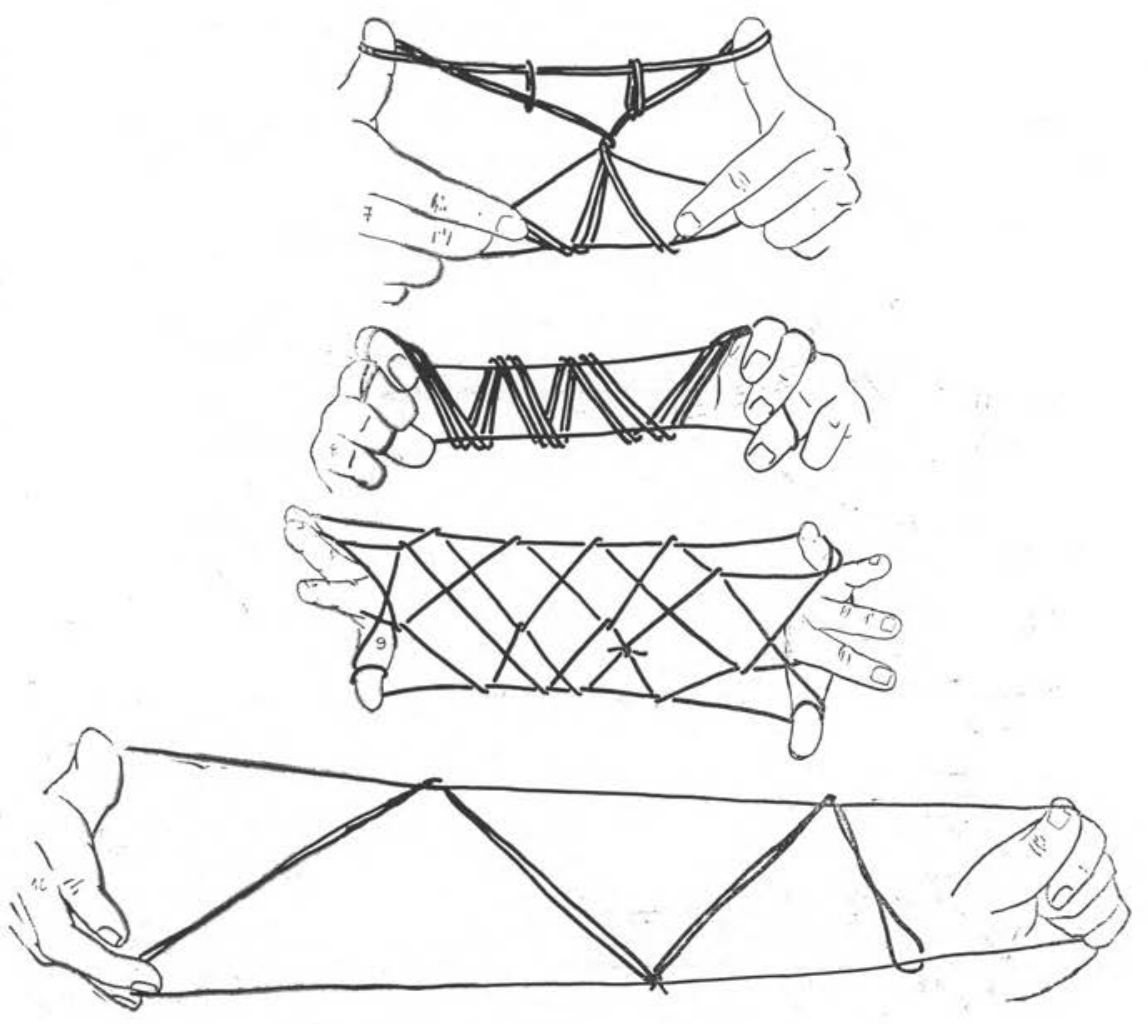

Fig. 7-10. - Juegos con hilos indígeuas (explicación en pág. 9)

Familiar, el Patizo, Juan del Sombrero Grande, y en religión popular, el culto de la Telesita.

Las creencias antedichas, aunque corresponden al mundo de los adultos, son sin embargo, conocidas y referidas por los niños en las escuelas tal como lo he podido comprobar.

Es frecuente la adivinanza, en que tienen importante papel los elementos autóctonos, principalmente las voces indígenas por ejemplo: 

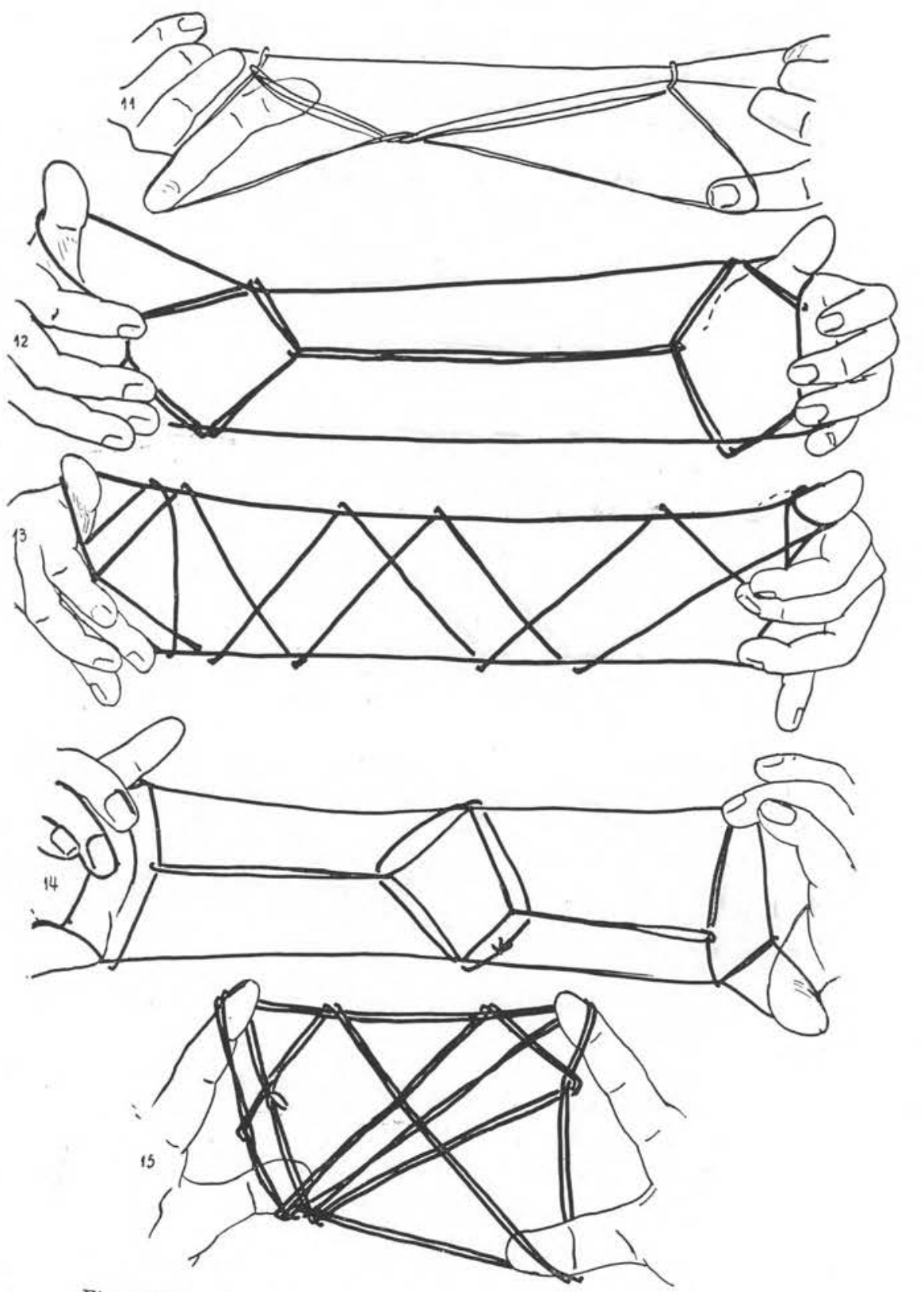

Fig. 11-15. - Juegos con hilos indígenas (explicación en pág. 9) 
Pisa que pisa

Antarea $y$ petisa

$$
\begin{gathered}
\text { Resp. - La ojota (calzado indígena semejante } \\
\text { a la sandalia de cuero) }
\end{gathered}
$$

En alto vive, en alto mora,

En alto teje la tejedora.

$$
\text { Resp. - La araña. }
$$

Estas dos adivinanzas muestran evidentemente aspectos de la vestimenta y de la artesanía típicos de la zona norteña. Y hay muchas más que adivinan la baraja, la empanada, la garrapata, la caña, el año, la naranja, etc.

Son de difusión nacional los de origen europeo tales como don Juan de las Casas Blancas, la rayuela, caballos y caballeros.

Es indudable que tanto en lo expuesto como en otros juegos de placer, de competencia, de oposición de los sexos, en donde los varones disfrutan sus luchas competitivas y las niñas se dedican a las formas de imitación de los oficios, evidentemente, reflejan la cultura europea con un colorido de lo autóctono que se manifiesta, tanto en las voces, como en la adaptación sintetizada de las costumbres tradicionales, señalando la intensidad de la cultura folk.

Frente a la enumeración de los comunes juegos europeos mencionados, se destacan nítidamente el valor y la influencia que ejercen los que son originariamente indigenas.

En algunos casos no hay casi contacto entre los niños criollos y aborígenes, otras veces los niños son bilingües y mantienen una influencia mutua. En resumen, tiende a ser folklorizado el entretenimiento infantil que se practica en el recreo escolar.

En la misma zona y entre grupos autóctonos del Chaco salteño, he podido documentar algunos de los juegos, que si bien es cierto, son conocidos principalmente por los chicos indígenas, son también practicados por los criollos. A continuación, señalo algunos entretenimientos recogidos entre indios matacos, tobas, chané y tapieté, cuyo tipo tiene mayor vigencia dentro del grupo tribal.

Kalaitaj (pies de fuego). Tribu mataco.

Lo describieron, además, los tapieté; es un juego prohibido por pertenecer a la hechicería, pero los niños lo hacen a escondidas de los 
mayores. Atanse tizoncitos encendidos en las canillas y saltan y caminan de noche cerea del monte.

Pandango (cangrejo) o Katum tum tum (imitando los cangrejos). Tribu toba.

Cuando están en los ríos, las chicas, de dos en dos y frente a frente, se toman de las manos, se zambullen y deben salir a la superficie sin soltarse.

Laltje (río). Este juego se llama también Ticomayo o Tucumayo. o del agua. Tribu mataco.

Juegan muchachos y chicas. En el agua, un muchacho persigue a. los demás; cuando llega uno de sus perseguidos, debe agarrarlo con una mano y, con la que le queda libre, lo toma por la cabeza zambulléndolo repetidas veces.

Chochomena (viejita bruja). Tribu toba.

Una chica o muchacho está en el suelo de antarca y tiene un tizoncito encendido en la mano; más allá, una fila de jovencitos lo llama ; éstos se aproximan, no lo ven y le pasan por encima. Alguien lo pisa. Entonces el caído se levanta, y con su tizón amenazante lo persigue en zig-zag.

Tojnaj, también Hokuánh (sapo o rana). Tribu mataco.

Forman una hilera sentados y van arrastrándose en esa posición: balanceándose, imitando el andar del sapo.

Pohó (hormiga). Tribu toba.

Las "hormigas" son dos filas de muchachos sentados frente a frente en el suelo, con las piernas recogidas para dejar un senderito. Viene un chico caminando por él; mientras camina trata de esquivar las "hormigas" que pellizean las canillas al pasar; la esencia del juego está en aguantar hasta salir del senderito.

Sueloj (la sandía). Tribu mataco.

Imaginan que son sandías y se ponen uno al lado del otro de antarca sobre el suelo. Allí quedan. Llega el "dueño" de las sandías y quiere 
elegir una madura, entonces les va dando un "tincazo" sobre el estómago. Cuando suena fuerte es que está madura, por eso hinchan el estómago para que suene más.

\section{JUEGOS CON HILOS INDIGENAS}

Explicación de las figuras: el número de la primera columna señala el de la figura correspondiente; en la segunda columna se anota su significado; las tres últimas columnas indican en que tribu fueron observados.

\begin{tabular}{|c|c|c|c|c|}
\hline \multirow{2}{*}{ Número } & \multirow{2}{*}{ Significado } & \multicolumn{3}{|c|}{ Tribu } \\
\hline & & Mataco & Maceá & Chahuanco \\
\hline 1 & Chujthichas (pipa) ............ & + & & \\
\hline 2 & «Nido de pájaro»............... & + & $\cdots$ & + \\
\hline 3 & Potsejlai $\ldots \ldots \ldots \ldots \ldots \ldots \ldots \ldots$ & + & & \\
\hline 3 & Nibouy ypana $\ldots \ldots \ldots \ldots \ldots \ldots \ldots$ & & & + \\
\hline 4 & Fuialauuk $\ldots \ldots \ldots \ldots \ldots \ldots \ldots$ & & + & \\
\hline 4 & Yasutata............. & & & $+\cdots$ \\
\hline 5 & $\begin{array}{l}\text { "El hombre que sal a cazar pero en- } \\
\text { cuentra algo que le da miedo y re- } \\
\text { gresa } \ldots \ldots \ldots \ldots \ldots \ldots \ldots \ldots \ldots \ldots\end{array}$ & & + & : \\
\hline 6 & Semthlajutichu $\ldots \ldots \ldots \ldots \ldots$ & + & & \\
\hline 6 & «Tronco de palo borracho $\# \ldots \ldots \ldots$ & & + & \\
\hline 7 & Chujthiehas (pipa) ........... & + & & \\
\hline 8 & : Petluichn $\ldots \ldots \ldots \ldots \ldots \ldots \ldots \ldots$ & + & & \\
\hline 8 & $\begin{array}{c}\text { Mboy yere (viborita enroseada en el } \\
\text { palo) } \ldots \ldots \ldots \ldots \ldots \ldots \ldots \ldots \ldots \ldots \ldots \ldots \ldots \ldots\end{array}$ & & & + \\
\hline 9 & «Constelación de las 7 cabrillas ».... & + & + & \\
\hline 10 & $\begin{array}{c}\text { Pethluichu (árbol quemado por re- } \\
\text { lámpago) } \ldots \ldots \ldots \ldots \ldots \ldots \ldots \ldots \ldots\end{array}$ & & + & \\
\hline 11 & Pethluichu (comienzo del dibujo $n^{\circ} 10$ ) & & + & \\
\hline 12 & Auutsaj (chancho del monte)....... & + & & \\
\hline 13 & Bmaoy cuatiá (culebra de agua) .... & & + & \\
\hline 13 & Tsemlajuuolé (hoja de palo borracho) & + & & \\
\hline 14 & Yuchán ............... & + & & \\
\hline 15 & $\begin{array}{l}\text { Potsejlai (constelación de las } 7 \text { eabri- } \\
\text { llas) } \ldots \ldots \ldots \ldots \ldots \ldots \ldots \ldots \ldots \ldots \ldots \ldots \ldots\end{array}$ & + & & \\
\hline
\end{tabular}

Tales son algunos de los ejemplos que el folklore infantil ofrece en nuestro medio, unos corresponden al medio rural eriollo, otros. son típicamente indígenas. La influencia hispánica del siglo xvI per- 
siste en algunas formas culturales dentro de la ciudad y del ambiente rural y, contemporáneamente, en sitios distantes o no, existen otras que conocen y practican los niños aborígenes que asisten a la escuela nacional o a las faenas de recolección colectiva (por ejemplo: la zafra). Lo verídico es que tienen mayor influencia los juegos indígenas cuando pasan temporadas largas en el bosque o en el río con sus padres. A pesar del contacto con el blanco, conservan vivamente el rico repositorio de su folklore. Sin embargo y aunque se practican bien definidas en el estilo de cada cultura, aparecen algunos préstamos que modifican las formas clásicas correspondientes a cada grupo, aborigen o de origen hispano. Estamos en presencia de una doble transculturación.

\section{BIBLIOGRAFIA CONSULTADA}

Andersen, J. C. Maori string games. Science and Technology. The New Zealand Journal, t. 8, $\mathrm{n}^{\circ} 4,1926$.

Arnott, J. Los toba-pilagá y sus guerras. Rev. Geogr. Americana no 7, 1934.

Battini, B. E. V. de. El juego. Cuestionario para la recogida del léxico regional y local. Estudio filológico folklórico. Consejo Nac. de Educación. Buenos Aires.

Cardona, M. Algunos juegos de los niños de Venezuela. Min. de Educación, Dirección de Cultura y Bellas Artes. Caracas, 1964.

Cascudo, L. Da Camara. Alguns jogos infantis do Brasil. Douro Litoral, $5^{\text {a }}$ serie, no 7 -8. Porto.

Catálogo de la colección de folklore donada por el Consejo Nacional de Educación. Inst. Literatura Arg., Fac. Filos. y Letras, 6 vols. Buenos Aires 1925-38.

Huizinga, J. Homo ludens. México, 1946.

Lehmann-Nitsche, R. Mitología sudamericana. V. La astronomía de los matacos. Rev. Mus. La Plata, t. 27. 1923.

- Mitología sudamericana. VI. La astronomía de los tobas. Ibidem, t. 27. 1923.

- Mitología sudamericana. VII. La astronomía de los chiriguanos. Ibidem, t. 28. 1924.

Martínez-Crovetto, R. Algunos juegos de los indios vilelas. Etnobiológica no ${ }^{\circ}, 1968$.

- Juegos y deportes de los indios guaraníes de Misiones (República Argentina). Etnobiológica $\mathrm{n}^{\circ} 6$.

Métraux, A. Etudes sur la civilisation des indiens chiriguano. Rev. Inst. Etnol. Tuc. 1 (3) : 473-479. 1929.

- Les indiens kamakan, pataso et kutaso d'après le journal de route inédit de l'explorateur français J. B. Douville. Ibidem 1 (2) : 239-293. 1930. 
Millán de Palavecino, M. D. Jeux infantins indigènes de Nord Argentine $\epsilon$ t Sudamérique. (Trad. de M. de Romagna.) Informe para el Instituto Real Belga de Folklore. Bruselas, 1964.

- Juegos infantiles criollos e indigenas en el norte argentino. Mesa redonda de Folklore, Inst. de Estudios Folklóricos de Tucumán, 1958. M/s.

- Valores de los dibujos tallados en los juegos de azar de los tobas. M/s.

Palavecino, E. Los indios pilagá del río Pilcomayo. Anal. Mus. Nac. Hist. Nat. "Bernardino Rivadavia", t. 37. 1933.

- Mitología chaqueña. M/s.

Rydén, S. South American string figures. Gothia t. 2. 1934.

Van Gennep, A. Manuel du folklore français contemporain. Vol. 4. Paris. 1933. 


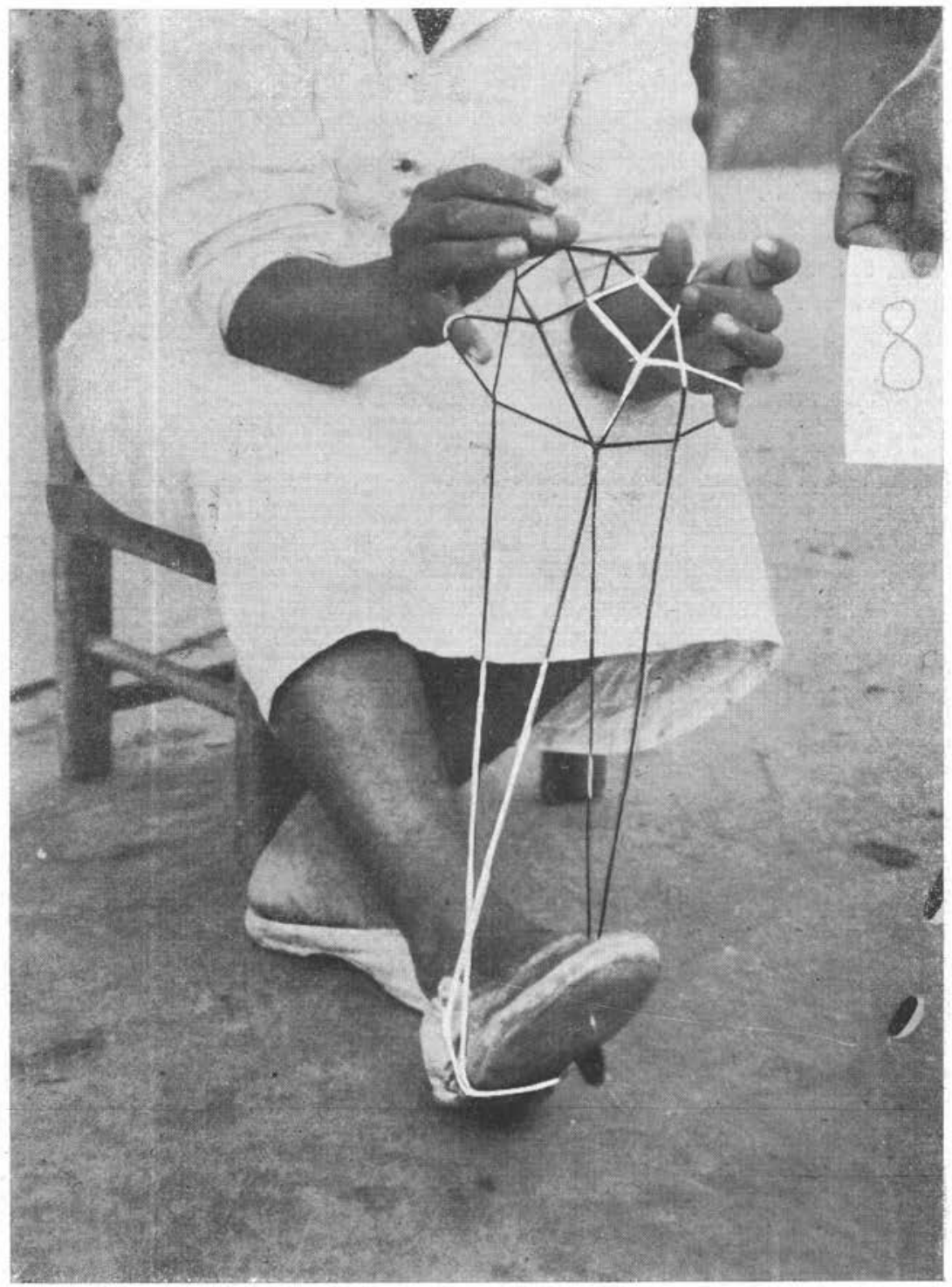

Iám. I. -- Mujer mataca mostraudo la ejecución de un juego de hilo con ayuda del pie 


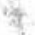

72

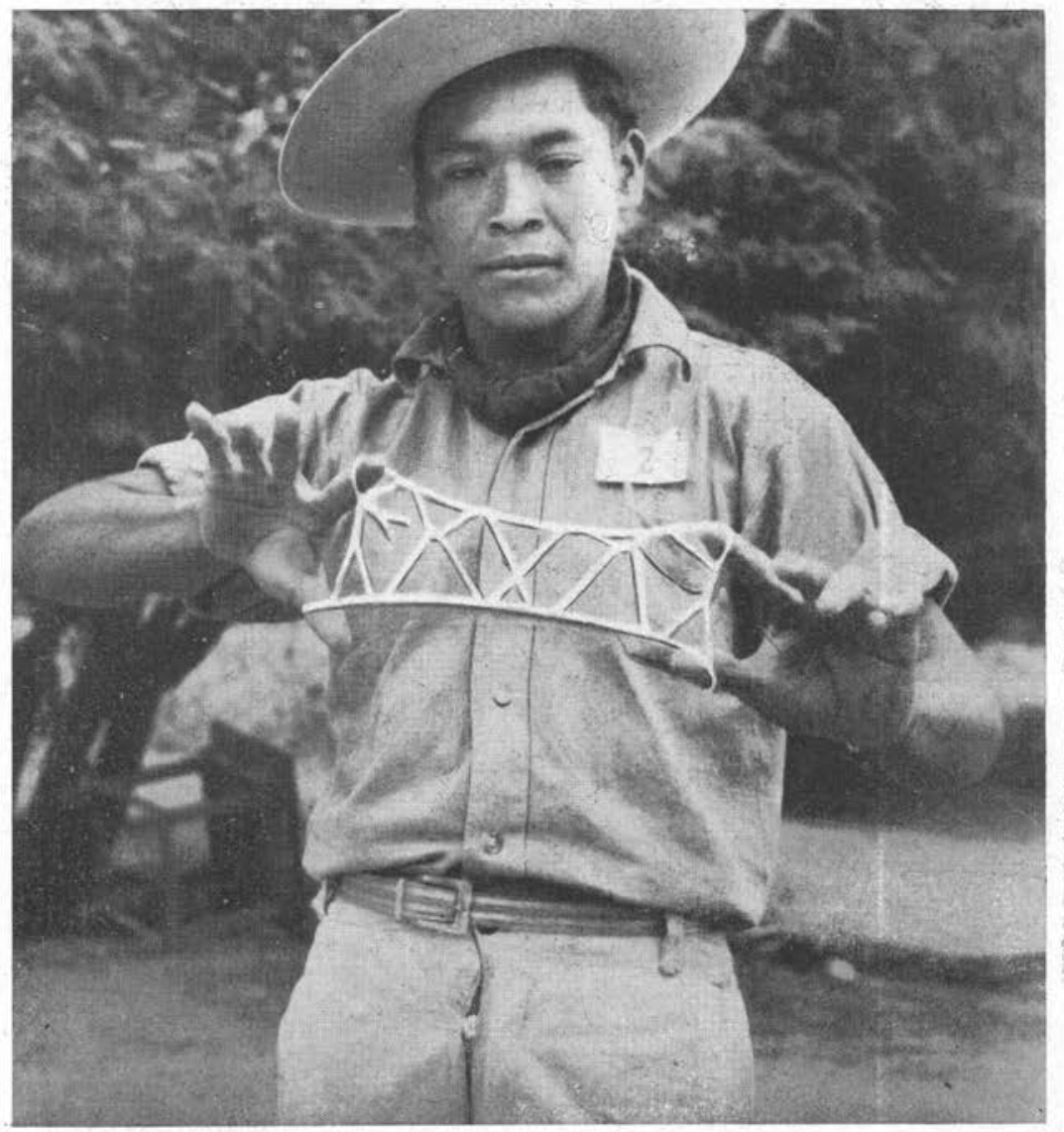

Lám. II. - Joven tapí haciendo el * dibujo de rílora * 


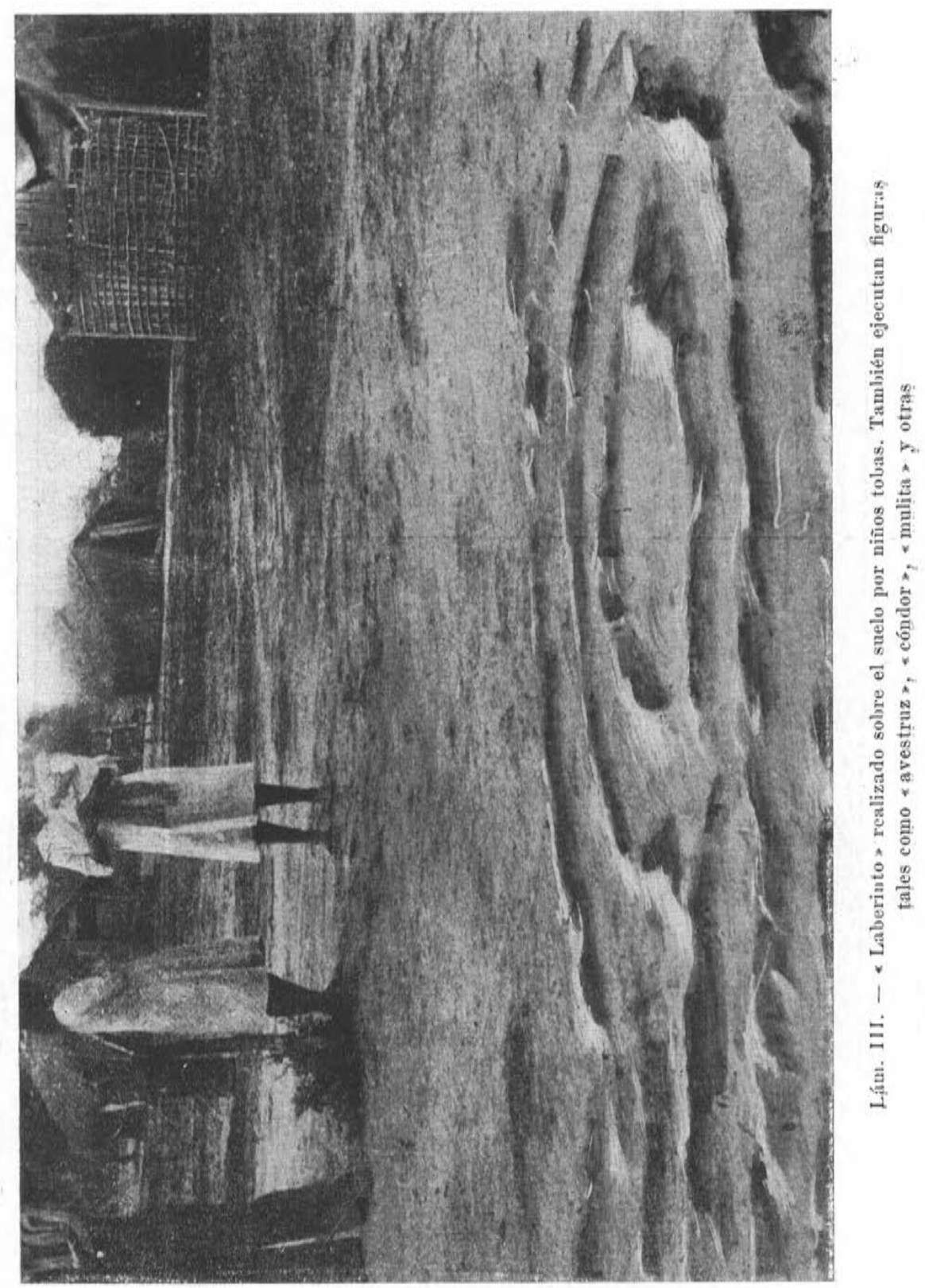

